\title{
Whistleblowing and Whistleblower Protection in South Africa (2001-2015): A Path Traversed
}

\author{
Abel J. Diale \\ Tshwane University of Technology, Pretoria, South Africa
}

\begin{abstract}
Whistleblowing and whistleblower protection legislation has gained considerable amount of attention in recent past. The recognition of whistleblowing, with all its associated features, has become one of the important key features of the accountability infrastructure in modern organizations, with the potential for being advocacy for organizational integrity. As a result, there has been a flurry of legislations promoting and protecting whistleblowing and whistleblowers respectively. Open and honest disclosure within the realm of the law, has proved to be dangerous and considered a treasonous act, with the likelihood of getting one's image tarnished or worse, silenced. This assertion is made in view of the limited scope and prescriptive measures provided for the current South African legislation, Protected Disclosures Act 2000 (Act 26 of 2000) and the proposed Protected Disclosures Amendment Bill 2015. This paper contends that there is still a long way in ensuring that whistleblowing becomes an integral part of the organizational culture in South Africa and the general public.
\end{abstract}

Keywords: whistleblowing, protected disclosure, whistleblower protection

Whistleblowing phenomenon has come a long way in its evolution as a central feature of open, responsible, democratic, and ethical system of governance. Some of the aspects that could be attributed to its revolutionised importance relate to, among others, man-made tragedies that have engulfed nation states across the globe, corporate scandals become major headlines resulting in major embarrassments and the pressure by international and multilateral bodies and civil society groups to adopt legislation that would safeguard those who disclose acts of wrongdoing, unethical and dangerous practices within organizations. What has become significant in these developments is that, national governments, especially of the developing world (South Africa included) which opted to introduce whistleblower protection legislation, tend to lack enforcement mechanisms, and most importantly, the burden of proof resides with the individual whistleblower with the result that the price (financial, psychological, and professional) that whistleblowers pay, becomes astronomical and at times, has tragic consequences despite protection provisions espoused in the legislation (Uys, 2008) ${ }^{1}$.

This paper is an attempt to unravel some underlying aspects pertaining to the South African framework of whistleblower protection through the lens of the Protected Disclosure Act (herein referred to as PDA) 2000 (No. 26 of 2000) and the Companies Act 2008 (No. 71 of 2008). In essence, this is the review of the progress thus is far achieved and as a follow-up to the earlier works by scholars and practitioners alike since the promulgation

Corresponding author: Abel J. Diale, Master of Public Administration (Executive) and a doctoral candidate, Tshwane University of Technology, Pretoria, South Africa; research fields: protected disclosure, whistleblowing, corporate social responsibility, local government studies, business and public sector ethics, organizational integrity.

${ }^{1}$ Retrieved from http://www.corruptionwatch.org.za/whistleblowers-champions-of-our-times/. 
of the PDA. Analysis will be made utilizing both primary (legislation) and secondary data. The paper will start by alluding to the theoretical underpinnings on the concept of whistleblowing, followed by the respective legislation as indicated above and the analysis on the intricacies of the South African system. This will be done by highlighting some of the tragic (anecdotal) cases that have bedevilled the system against the accolades that have been bestowed on the legislation and its intents. Concluding remarks will be advanced to allow the policy-makers and practitioners to consider.

\section{Whistleblowing: Conceptual and Definitional Construct}

Broadly speaking, according to Jubb (1999, pp. 78, 83), whistleblowing is presented as dissent, in response to ethical dilemma, in the form of a public accusation against an organization. It is a key way to deliver accountability (Calland \& Dehn, 2004, p. 11). As Banisar (2011) pointed out, whistleblowing is a means to promote accountability by allowing for the disclosure by any person of information about misconduct while at the same time protecting the person against sanctions of all forms. The author further recognises that whistleblowing relates to internal and external disclosures and should apply to all organizations: public and private. Further, Jubb (1999, p. 83) stated that whistleblowing presents two role-related tensions. These consist of: (1) ethical conflict between personal and organizational values, which presents value-laden decision; and (2) ethical dilemma of conflicting loyalties to the targeted organization that conflicts with, loyalty to self (integrity), and perceived responsibility to others, e.g. professional bodies/associations or the general public.

Diale and Holtzhauzen (2005, p. 11) quoting Calland and Dehn (2004), attested in support of the exploration above that, whistleblowing is about basic issues which lie at the heart of human activity, it covers loyalty and the question of dubious practices. It concerns communication and silence; it is about practicing what one preaches and about leadership. It focuses on the responsibility toward others and the accountability of those in charge. This view resonates with one articulated by Yeoh $(2014$, p. 462) that overall, the utility of whistleblowing extends from revealing information that is critically important for public life, to institutions seeking to improve their internal management to make it more accountable and as an instrument in support of good governance and a manifestation of a more open organization culture. An acknowledgement is also made by Banisar (2011) that whistleblowing procedures are only parts of a larger package of laws and cultural activities needed to move towards a more open society, it is more of an ethical issue, it focuses on the information not the person, it is also useful for bodies that want to improve their internal management to make it more accountable. However, whistleblowing is not without repercussions or barriers for those who disclose in the spirit of kick-starting corrective measures to undesirable behaviour or intentions. As Diale (2005, pp. 270-271) succinctly put it, the hostility with which whistleblowers have often been viewed and treated, has been based on the perception that they undermine the traditional norms of working behaviour which would be likely to prompt considerable hostility and various forms of reprisals and retaliation. The key hindrances to whistleblowing relate to: fear of retaliation, legal liability, duty of loyalty and confidentiality, secret acts/legislation, and libel and cultural barriers among others. De Maria (2002, p. 4) once remarked, "whistleblowing is reminiscent of a swim in shark infested waters, in which death faces a person, as distinct from to a career and psychological health, awaits those men and women of good conscience".

The central theme underlying this paper is that, whistleblowing, with its associated advocacy and the resulting retaliations, is all but human activity, and no amount of law can effectively regulate it. Despite all the negativity and risks associated with whistleblowing, there has been a considerable amount of energy geared 
toward making it part and parcel of modern system of governance. It is on these bases that, the next section looks into South Africa's obligations (international, regional, and domestic) regarding promoting whistleblowing and protection of whistleblowers respectively.

\section{International Conventions and Agreements on Whistleblowing and the Protection of Whistleblowing-A Brief Overview}

This paper considers only those international agreements/conventions that South Africa is obligated after becoming a signatory to and ratifying them. The first relates to the United Nations Convention on Anti-corruption of 2005. This international instrument saw its emergence as a result of the United Nations Convention Against Corruption (UNCAC) which was spearheaded in 2000, with the final version being adopted in 2003, and was finally adopted in 2005.

As of January 6, 2015, a total of 132 countries had signed and ratified the Convention, South Africa was one of them. To be precise, South Africa signed the Convention on December 9, 2003 and later ratified it on November 22, 2004². Of interest to this paper, it relates to the Convention's Articles 32 and 33 respectively. Article 32 makes provision for effective protection from potential retaliation or intimidation of witnesses and experts who give testimony concerning offences in accordance with the Convention and, for their relatives and other persons close to them. But of more significance, it is Article 33 dealing with protection of reporting persons. In this case, an assumption is being made that these reporting persons refer to whistleblowers and their envisaged protection. It stipulates that:

Each State Party (ESP) shall consider incorporating into its domestic legal system, appropriate measures to provide protection against any unjustified treatment for any person who reports in good faith, and on reasonable grounds to the competent authorities any facts concerning offences established in accordance with the Convention.

As Moller-Holst (n.d.) put it, these two Articles are aimed at providing for procedures for the physical protection of witnesses, experts, victims, and reporting persons. It will be noteworthy to evaluate how such protection is implemented at individual state level. It is also interesting to note that South Africa enacted its Protected Disclosure Act 2000 (Act 26 of 2000) with its proverbial fraternal twin legislation in the form of the UK's Public Interest Disclosure Act (PIDA) 1998, five and seven years respectively ahead of the final adoption of the UNCAC. An illustration of these two pieces of legislation is comprehensively dealt in Diale and Holtzhauzen (2005, pp. 13-14).

The second such Agreement/Convention is the African Union Convention on Preventing and Combating Corruption (herein referred to as the AU Convention). This Convention was adopted by the 2nd Ordinary Session of the Assembly of the Union held in the Capital of Mozambique, Maputo, on July 11, 2003. In its Preamble, AU Convention, among others, is concerned about the negative effects of corruption and impunity on the political, economic, social, and cultural stability of African States and its devastating effects on the economic and social development of the African peoples; acknowledges that corruption undermines accountability and transparency in the management of public affairs as well as socio-economic development on the continent; and is convinced of the need to formulate and pursue, as a matter of priority, a common penal policy aimed at protecting the society against corruption, including the adoption of appropriately legislative and adequately preventative measures. Further, in terms of Article 2 (5), the key objective of the AU Convention

${ }^{2}$ Retrieved from http://www.unodc.org/unodc/en/treaties/CAC/signatories.html. 
related to this paper is "to establish the necessary conditions to foster transparency and accountability in the management of public affairs". This objective, the paper contends, is a crucial and central theme to the advocacy for whistleblowing as extrapolated in the previous section. It is also related to Article 3 that deals with Key Principles of the Convention. More importantly, Principle 3 advocates for the undertaking by member states to abide by among others, transparency and accountability in the management of public affairs.

In terms of Article 5, the following legislative and other measures speak to the scope of this paper. These are:

(1) Adopting legislative and other measures to protect informants and witnesses (read whistleblowers) in corruption and related offences, including protection of their identities;

(2) Adopting measures that ensure citizens report instances of corruption without fear of consequent reprisals;

(3) Adopting national legislative measures in order to punish those who make false and malicious reports against innocent persons in corruption and related offences;

(4) Adopting and strengthening mechanisms for promoting the education of populations to respect the public good and public interest, and awareness in the fight against corruption and related offences, including school educational programmes and sensitization of the media, and the promotion of an enabling environment for the respect of ethics.

Clause 8, if one were to further interrogate it, it clearly points to the need for ensuring that the public at large is an integral part in the efforts of enabling an open, responsible, accountable, and transparent system of government and as such, key to achieving such ideals lies at the heart of educational initiatives to bring to fruition active citizenry. Closely related to this specific clause is Article 12 that deals with Civil Society and Media (1)-(4).

According to Article 12, State Parties made undertaking to the following:

(1) Being fully engaged in the fight against corruption and related offences and the popularisation of the Convention with full participation of the Media and Civil Society;

(2) Creating an enabling environment that will enable Civil Society and the Media to hold governments to the highest levels of transparency and accountability in the management of public affairs;

(3) Ensuring and providing for the participation of Civil Society in the monitoring process and consult Civil Society in the implementation of the Convention;

(4) Ensuring that the Media is given access to information in cases of corruption and related on condition that the dissemination of such information does not adversely affect the investigation process and the right to a fair trial.

The above exploration indicates the magnitude of the efforts being taken by the African leadership in promoting open, transparent, accountable, and ethical system of governance. As to whether the provisions of this Convention have been embraced for its intended purpose, it is a matter for another research effort. What should be borne in mind is to gauge the South African system against this Convention.

The third Agreement/Convention is the Southern African Development Community (SADC) Protocol Against Corruption (herein referred to as the SADC Protocol). The SADC Protocol represents another regional instrument on anti-corruption in Africa, after the AU Convention, which also provides whistleblower protection. It was signed by 14 African Nations represented by the Heads of State or Government or duly authorised representatives on August 14, 2001 in Blantyre, Malawi.

In its Preamble, the SADC Protocol, among others, is concerned about the adverse and destabilizing effects of corruption throughout the world on the culture, economic, social, and political foundations of society; 
notes that corruption is a serious international problem which is presently the subject of concerted action in other parts of the world and one which countries in every stage of development should tackle as a matter of urgency; takes cognizance of the Resolutions agreed on initiatives to fight corruption in the region; acknowledges that corruption undermines good governance which includes the principles of accountability and transparency; recognises that demonstrable political will and leadership are essential ingredients to wage an effective war against the scourge of corruption and; and reaffirms the need to eliminate the scourge of corruption through the adoption of effective preventative and deterrent measures and by strictly enforcing legislation against all types of corruption and fostering public support for these initiatives. This aspect could be construed to imply whistleblowing and whistleblower protection measures.

Article 2 of the SADC Protocol speaks to its purposes as follows:

(1) To promote and strengthen the development, by each of the State Parties, of mechanisms needed to prevent, detect, punish, and eradicate corruption in the public and private sectors;

(2) To promote, facilitate, and regulate cooperation among the State Parties to ensure the effectiveness of measures and actions to prevent, detect, punish, and eradicate corruption in the public and private sectors;

(3) To foster the development and harmonization of policies and domestic policies of the State Parties relating to prevention, detection, punishment, and eradication of corruption in the public and private sectors.

In terms of Article 4 (Preventative Measures), the SADC Protocol envisages that each State Party undertakes to adopt measures which will create, maintain, and strengthen:

(1) Systems for protecting individuals who, in good faith, report acts of corruption;

(2) Institutions responsible implementing mechanisms for preventing, detecting, punishing, and eradicating corruption.

A cursory look of the provisions of the SADC Protocol so far indicated, provides an impression of a committed regional community, however, if one were to provide preliminary evidence of how many State Parties within SADC have actually promulgated and are currently enforcing such legislation, one will be inclined to conclude that this Protocol will remain just that, a Protocol. The interesting part of the SADC Protocol and South Africa as a signatory is that South Africa enacted what is envisaged by this Protocol a year earlier before it could be signed (August 14, 2001) and ratified (May 15, 2003).

Another International Convention that South Africa subscribes to is the OECD (Organization for Economic Co-operation and Development) Anti-bribery Convention that established binding standards to criminalize bribery of foreign public officials in international business transactions, the 2003 OECD Guidelines for Managing Conflict of Interest in the Public Service. Even though South Africa is a non-member country of the OECD, but since 2007, it has been a party, has working relation with the OECD organization and has adopted this convention. It needs to be emphasized that, for there to be whistleblowing activities and their envisaged protection, corruption (this includes bribery and its solicitation, rent-seeking, undue influence on tender and business licences awards, as well as conflict of interest) is the central epidemic that has to be addressed. It is in this sense that corruption, the epicentre of the illicit economy, is the raison d'etre for whistleblowing activities, these two phenomena cannot be separated.

\section{South African Legislative Framework for Whistleblowing and Whistleblower Protection}

South Africa's whistleblowing regime, or the principal legislation, the Protected Disclosure Act, 26 of 2000, is inspired by the UK's Public Interest Disclosure Act of 1998. For an exposition of this submission, we 
can see De Maria (2002), Diale and Holtzhauzen (2005), Martin (2010), and Botha and Van Heerden (2014). This assertion is further captured by Patel (2013, p. 25) quoted in the DLA Piper's Report in which he states “.... The whistleblowing framework in South Africa has specific legislative protection for whistleblowers in the workplace, similar to the legislation in place in the UK”.

A study by DLA Piper's Employment Group titled "Whistleblowing: An Employer's Guide to Global Compliance” was published in 2013, placed South Africa's whistleblowing regime among the top five (5) across five continents with a rating of three stars (i.e. overall protection rating). The top five countries are the United States, United Kingdom, Japan, China, and South Africa. Whistleblowing regimes of these countries, according to the study, are considered to have Expressed Protection. Eight (8) aspects were used as a measuring tool which, in order of chronology, are the following: (1) Express laws; (2) General dismissal laws; (3) Protection against retaliation; (4) Encouraging external reporting; (5) Internal reporting encouraged; (6) Consultation on whistleblowing procedures required; (7) Board/management investigation of disclosures required; and (8) Government/regulatory incentives to disclose. According to the study, South Africa fared positively in the aspects (1), (2), (3), and (5). It needs to be pointed out that the study report is silent on the weighting of these aspects. Further, the study report paints a glorious picture and offers praises in the following manner: "South Africa leads the way, by offering progressive and extensive protection for whistleblowers" (DLA Piper, 2013, p. 9). However, the report further maintains the benchmark to qualify for whistleblowing protection is set very low, to allow for protection even if the whistleblower may not have irrefutable proof of the truth of the disclosure. As to the consideration made to arrive at this conclusion, it remains a mystery, or for the lack of a better word, a mystique considering the wealth of information, as presented by the research studies cited in the next paragraph. Contrary to this conclusion, it is the assertion made by Open Democracy Advice Centre (ODAC) (2015) which states “...considering the actual experiences of citizens who blow the whistle in South Africa, it becomes clear that the ambitious constitutional principles that promote transparency are not enough to create a safe environment for those that speak out on wrongdoing”. Also, a thoroughly analytical work of the whistleblowing in South Africa, not "the good on paper" analysis of the report has been provided, which could have assisted in providing some insights on the tragedies that befell those citizens/employees of conscience in their pursuit of a just, transparent, and accountable system of governance through whistleblowing.

A glimpse of one of the major cases that involve a whistleblower in testing the veracity of the claims advanced by the report would have accorded the author(s) of the report an opportunity to interrogate some of the claims advanced. The cases concerned are: Case No: JS 898/04 in the Labour Court of South Africa (on November 2, 2006), in the matter between M. M. Tshitsonga (Applicant) and the Minister of Justice and Constitutional Development (First Applicant) and Director General of the Department of Justice and Constitutional Development (Second Responded) and the subsequent Appeal Case (Case No: JA 6/2007). The two cases provide an in-depth insight into how the whistleblower protection regime in South Africa is susceptible to manipulation (the power relations between the employer and employee), its narrow focus on employment relations, and the costs (measurable and immeasurable) to the whistleblower. To provide a brief overview of the lived experience of this whistleblower, the situation began in 2003 while Mike Tshitsonga was an employee in the Master's Office of the Department of Justice. He attempted to make disclosures internally as per the legislation, which related to incidences of corruption and nepotism he had uncovered. This was as a result of becoming aware of gross and consistent abuses of liquidations. However, there was no adequate action taken on his allegations, and this led him to eventually make his claims to the media, which included 
allegations against the Minister of Justice. He was suspended from his job two months later, and this led to what would be his long battle against his unfair suspension in the Labour Court. Eventually, a settlement was reached, but only after significant hardship was experienced by both Mike and his family.

The other contention relates to the apparent lack of consideration of research work and other studies conducted over time before this report could be published. This, which the paper maintains, could have accorded the authors of the DLA Piper's report a chance to interrogate the relationship between the law and reality/practice.

The research initiatives include the South African Law Reform Commission: Project 123: Protected Disclosures Report of November 2007, Tina Uys' 2008 study "Rational Loyalty and Whistleblowing: The South African Context”, and the report by Patricia Martin (2010) titled "The Status of Whistleblowing in South Africa-Taking Stock". The intention is not to disregard other scholarly publications on the subject. The following is a summary of what is alluded to in respect of the efficacy or lack thereof of the PDA:

(1) Limited scope of application-Not all whistleblowers are protected; this aspect relates to the exclusion of citizen whistleblowers as expressed in the AU Convention as alluded to earlier. Only (full-time) employees are accorded the protected disclosure status at the exclusion of contract/agency workers, former employees, prospective employees, volunteers, or company pensioners;

(2) Not all disclosures about unlawful or irregular conduct by organizations, officials or people linked with organizations are protected;

(3) The range of recipients to whom protected disclosures may be made is too limited; this relates to the South African regulatory framework (as espoused in the PDA), is populated by a host of constitutional oversight bodies (e.g. Public Service Commission), statutory regulatory bodies (e.g. Financial Services Board), and a host of professional oversight bodies (e.g. Health Professions Council of South Africa). These structures have two common features: (a) All of these structures are mandated to receive and act on complaints of irregularities and corruption within various structures and organizations; and (b) Disclosures to these structures are not protected by the PDA. The PDA only permits disclosures under an elevated burden of proof to two investigative agencies, i.e. the Public Protector and the Auditor General;

(4) A failure to compel pro-active measures by organizations; under the current PDA, there is no obligation imposed on organizations (imposed by any law), to take pro-active action to develop and implement whistleblowing policies and processes, and to take action when a report is made;

(5) Inadequacy of the forums to resolve disputes; the current set-up is court-based, which makes justice inaccessible to those who have suffered occupational detriment and may not have the luxury of unlimited financial muscle;

(6) Limitation of protection against an "occupational detriment"; this relates to the narrow Labour Relations Act induced interpretation of occupational detriment. As indicated, the numerous kinds of reprisal that whistleblowers are faced may not necessarily stand in courts of law (e.g. ostracizing);

(7) A failure to protect the confidentiality of whistleblowers; on this aspect, the reason why the PDA fails dismally is that it does not make any obligation on organization to protect the identity of whistleblower after a disclosure has been made. This aspect runs contrary to the provision of the AU Convention, Article 5 (5);

(8) Limitations placed on the Remedies for Whistleblowers; again this aspect is interpreted in terms of the Labour Relations Act according to the two categories: (a) the award is capped for unfair labour practice (12 months' salary); and (b) automatic unfair dismissal (24 months' salary). Also, the limitations of the PDA 
prohibit punitive damages, civil liability, and are limited to claims against the employer only. No claims are against the third person. The two court cases cited in the previous section provide a clear picture in this regard.

The other piece of legislation worthy of mention is the Companies Act (71 of 2008), particularly section 159 (1)-(7). These provisions have been succinctly summarised by Martin (2010, pp. 90-91):

(1) The act expands significantly the ambit of protection against reprisals beyond an "occupational detriment" to include reprisals that cause any detriment as well as an express or implied threat to cause any detriment;

(2) The act also expands the remedies and damages that are available but limited by the Labour Relations Act (LRA) as espoused by the PDA. The principles of general damages take centre stage;

(3) The act allows a whistleblower to claim punitive damages from any person for victimising, or even threatening to victimise the whistleblower if such a disclosure is a protected disclosure;

(4) It introduces immunity from criminal, civil, and administrative liability that may arise out of a discourse made by one of the protected categories of people;

(5) It also introduces a "qualified protection" of the whistleblower's identity.

It will also be valuable to reflect on the Practical Guidelines for Employees in terms of the Protected Disclosure Act (Act 26 of 2000). The introductory section of the guidelines states the following:

By remaining silent about corruption, offences or other malpractices taking place in the workplace, an employee contributes to, and becomes part of, a culture of fostering such improprieties which will undermine his or her own career as well as be detrimental to the legitimate interests of the South African society in general. Every employer and employee has a responsibility to disclose criminal and other irregular conduct in the workplace.

A cursory look at this assertive introduction, one would be inclined to believe that an element of obligation will be provided on the duty of the employer to investigate the disclosure of wrongdoing (as and when it is reported); the protection of the identity of a whistleblower; the mechanisms available to provide protection for whistleblowers; and to borrow Martin's (2010, p. 86) articulation, the lack of practical guidelines for South African organizations to develop organizational map of good governance, that is of value to the organization and which will engender confidence in the employee to blow the whistle. Related to this observation, ODAC (2015) also concurred in opining that what is at least a good-on-paper legislative landscape, the reality of whistleblowing in South Africa is that it can be a high-risk act with a variety of negative and long-lasting challenges for the living of the whistleblower.

Also of interest is the disclosure pathways provided in the Act and by extension, the guidelines. These are: Disclosure to a Legal Representative (Route 1); Disclosure to the Employer (Route 2); Disclosure to the Minister or Member of Executive Council (MEC, this is the title applied to Political Leadership of a Province) (Route 3); Specified Person or Body—This refers to either the Public Protector or the Auditor General (Route 4); and a General Disclosure (Route 5). In articulating route 2, the guidelines specifically affirm the utilization of anti-corruption hotlines, and implore employees to report through these channels. In the South African context, some reservations were expressed among others; the Public Service Commission (PSC) released its 2008 report on Measuring of the Effectiveness of National Anti-corruption Hotline: Second Biennial Report, in which the following remark was made:

While anonymous reporting of corruption is promoted through the NACH, this does create practical difficulties in that crucial information or evidence, if not supplied in the first instance, is difficult to obtain as callers cannot be traced for follow-up processes. 
A similar observation was also made by Calland and Dehn (2004, p. 8) that, as to the message, anonymity raises real problems as it makes the concern more difficult to investigate, the facts more difficult to corroborate and exclude the possibility of clarifying any ambiguous information or asking for more.

Route 5 reads in part:

An employee can even make a disclosure to any person, for example, a member of the press (people working for radio and television stations or newspapers), a police official of the South African Police Service or a person working for an organization which keeps watch over the public or the private sector.

This route, at face value provides a fallacious comfort to would-be whistleblowers.

The South African situation is the one full of contradictions; world-renowned Constitution and laws (on anti-corruption and whistleblowing) are accompanied by unabated silencing culture of those who are willing to risk their careers (and lives) in the protection of the noble principles of the Constitution and other laws meant for accountable, transparent, and good governance. Anecdotal evidence is abounded but only a few will be presented: The first case relates to that of Moses Phakoe (deceased) and Alfred Motsi, Municipal Councillors from the Rusternburg Municipality in the North West Province of South Africa. The two individuals presented a dossier of what they maintained as proof of fraud and corruption totalling millions of rands to the political leadership of the ruling party [ANC (African National Congress)], specifically to the Office of the Secretary General (Mr Gwede Mantashe); and to the Office of the President then run by H. E. Kgalema Motlanthe. The case would ultimately be assigned to the Minister in charge of Co-operative Governance and Traditional Affairs (the late Hon Shiceka) during a meeting in Rusternburg on March 12, 2009. The early evening of March 13, 2009, Phakoe's body was found slumped over the steering wheel of his car in his driveway with two bullet wounds (Tilley, 2014). This case and other similar ones which will be cited below, highlight the physical vulnerability of those blowing the whistle and the hardships that their families would be exposed to after their demise.

Another headline by one of the major print media outlets, the Mail and Guardian of September 18, 2014 reads "Hawks Whistleblower Slain". This relates to the gunning down of one Xola Banisi (September 2014), an employee of Bloem Water, (a parastatal of the Free State Province of South Africa) attached to the human resources division. It was reported that he had apparently lodged a complaint with the Public Protector's office, and was working with the Hawks: Directorate for Priority Crime Investigations anti-corruption unit on illegal dealings alleging "maladministration in that training contracts was issued, but that double payments were made to different service providers for the same training”3. What is intriguing about the case is that, $\mathrm{Mr}$ Banisi is said to have reported receiving death threats and reported these to the police. These are some of the tragic incidents, but a reality check of what whistleblowers are facing continuously in their pursuit of good governance. The other whistleblowers who suffered the same fate include but are not limited to: Buyisile Mkavu, a Municipal Councillor in the Nelson Mandela Bay Municipality, Eastern Cape Province at the time of his passing (August 2014) and Jimmy Mohlala (January 2009), the speaker of the Mbombela Municipality, Mpumalanga Province. What is of interest is that the reports indicate that the said individuals had followed the latter of the law in exposing corruption in their respective working environments. This brings to question the efficacy or lack thereof, of the current legal framework, its scope of protection, cultural imperatives of the society it intends to serve, and the practicality of its provisions.

\footnotetext{
${ }^{3}$ Retrieved from http://mg.co.za/print/2014-09-18-hawks-whistle-blower-slain.
} 
The above exploration indicates that whistleblowing or as is called in South African legal system, Protected Disclosures is not purely a labour-oriented endeavour as espoused in the PDA, to be handled using Labour Laws ex post facto, as if it is the employees' occupation at risk but, as in the cases above, there is more to whistleblowing (and its associated reprisals) than occupational detriment.

It is of interest to note that as per the principal legislation, the Protected Disclosures Act 2000 (Act 26 of 2000) whose commencement date was February 16, 2001, took almost 10 years and 6 months for the Minister of Justice and Constitutional Development to promulgate and publish, as per Section 10, Practical Guidelines for Employees to report impropriety (blowing the whistle). The Report by the South African Law Reform Commission (2007) as indicated above was central in the promulgation of the Protected Disclosures Amendment Bill, which was introduced to the National Assembly in December 2015, still to be ratified and enacted into law. However, a cursory look at this proposed bill, it is still apparent that central to whistleblowing regime and the associated protection, emphasis is still religiously placed on the labour relations paradigm. Also, evident from the proposed Bill is that no consideration has been made on (protection of whistleblowers) what one of the victimised whistleblowers had to say based on his experiences: "the power of large institutions means that victimization occurs in a variety of ways that leaves a whistleblower feeling assaulted from all sides" (ODAC, 2015). This expression found its way into the concerted efforts by civic and professional bodies in tackling the exposure/disclosure of corruption and wrongdoing.

What needs to be applauded on the part of the civil society and professional bodies is the establishment of the Anti-intimidation and Ethical Practices Forum (AEPF). This body was established (in January 2015) to help professionals in certain fields who are being intimidated for exposing corruption in the workplace. The forum has eight (8) founding organizations: Association of Certified Fraud Examiners of SA (ACFESA); Ethics Institute of South Africa (EthicsSA); the Institute of Directors of Southern Africa (IoDSA); the Institute of Internal Auditors of South Africa (IIASA); the Institute of Risk Management of South Africa; the South African Institute of Professional Accountants; and the South African Institute of Chartered Accountants (SAICA) ${ }^{4}$. Another initiative is the one provided by Whistle Blowers (Pty) Ltd founded in 2000. It offers a subscribing client, a cost effective 24/7/365 highly trained, multi-lingual, manned state of the call centre which enables client staff to report any irregular activities within an organisation. These irregular activities could include, but are not restricted to theft, fraud, bribery, unethical practices, and any other unlawful or dishonest activities. The approach adopted is implementing a whistleblowing system that is tailor-made to suit the client's needs and aligns with the company's culture, which guarantees employee buy-in (acknowledged and supported by most trade unions) and creates easy access to an anonymous "whistleblowing" line. The initial process is to educate all levels of staff on the mechanics and benefits of the system. The process includes conducting workshops and presentations to staff within the organisation ${ }^{5}$. These initiatives resonate with ideas postulated by ODAC (2015) that whistleblowers need direct assistance by way of creating a strong, informed, and consolidated network of civil society and state actors that are called upon to assist them.

\section{Concluding Remarks}

Whistleblowing is an essential element of building organizations of repute. Cases across the globe have demonstrated in the past that, applied to its maximum efficacy, it has the potential to rid organizations of

\footnotetext{
${ }^{4}$ Retrieved from http://corruptionwatch.org.za/new-forum-to-advise-protect-whistleblowers/.

${ }^{5}$ Retrieved from http://www.whistleblowing.co.za/about/.
} 
malpractices that may lead to their demise. However, South Africa's historical past colonial orientation becomes evident in this piece of legislation. This relates to the hegemony of Western epistemology on whistleblowing. The reason for such an assertion is primarily based on the interpretation of whistleblowing and the supposed protection of whistleblowers; little or no concern is given to the multitudes of cultures, the heterogeneous nature of the South African society and the belief systems on the meaning of whistleblowing and its interpretation. This paper recognizes that whistleblowing is a long-term act, with consequences continuing beyond the period of disclosure, with a guaranteed payback of retaliation of all sorts and, the adverse effects on one's personal life, family, career, and societal relations. This paper contends that, these aspects present one of the missing links to what whistleblowing in the South African context entails. In view of the above aspects, the following are some of the aspects worthy of consideration by policy-makers:

(1) The protection of the identity of whistleblowers needs to be made mandatory, even though this may be highly unlikely; however, efforts have been made to secure near-absolute solution;

(2) To consider the inclusion of citizen whistleblower in line with the AU Convention to ensure that general members of the public become active participants in the fight against graft;

(3) It should be a requirement for all employees of state organs, government departments, and private organizations to be educated through awareness campaigns, and be part of induction and development programmes; currently this is a responsibility of civic bodies and advocacy groups;

(4) Mandatory liability on those whose actions or in-actions could lead to whistleblower's lives being endangered or compromised.

It will also be worth considering the possibility of including, in Ethics Management Programs (EMP), whistleblowing and all its ramifications as an integral component of Public Administration syllabus.

\section{References}

African Union. (2003). African Union Convention on Preventing and Combating Corruption. Retrieved from http://www.au.int/en/sites/default/files/treaties/7786-sl-african_union_convention_on_preventing_and_combating_corruption -21.pdf

Banisar, D. (2011). Whistleblowing: International standards and developments. In I. E. Sandoval (Ed.), Corruption and transparency: Debating the frontiers between state, market and society. World Bank Institute of Social Research, UNAM, Washington, D.C.

Botha, M. M., \& Van Heerden, C. (2014). The Protected Disclosures Act 26 of 2000, the Companies Act 71 of 2008 and the Competition Act 89 of 1998 with regard to whistle-blowing protection: Is there a link? TSAR, 2, 337-358.

Calland, R., \& Dehn, G. (2004). Whistleblowing around the world: Law, culture and practice. Cape Town, ODAC \& PCAW.

Corruption Watch. (2012). Whistle-blowers: Champions of our times. Retrieved from http://www.corruptionwatch.org.za/whistle -bowers-champions-of-our-times

Corruption Watch. (2015). New forum to advise, protect whistleblowers. Retrieved from http://corruptionwatch.org.za/newforum-to-advise-protect-whistleblowers/

De Maria, W. (2002). Common law-Common mistakes: The dismal failure of whistle-blower legislation in Australia, New Zealand, South Africa, Ireland and the United Kingdom. Proceedings from the International Whistleblower Conference. University of Indiana, April 12-13.

Diale, A. J. (2005). Swimming against the tide-The plight of a whistle-blower in South Africa. Journal of Public Administration, 40(3.1), 269-279.

Diale, A. J. (2010). The role and importance of whistleblowing in building organizational integrity in the public sector: A theoretical exposition. Journal of Public Administration, 45(1.1), 295-305.

Diale, A. J., \& Holtzhauzen, N. (2005). Public or protected disclosure? The fallacy of whistle-blower protection in South Africa. Journal of Public Administration, Conference Proceedings, October 2005, pp. 10-19. 
DLA Piper. (2013). Whistleblowing: An employer's guide to global compliance. A study by the DLA Piper's Employment Group. Retrieved from https://www.dlapiper.com/en/us/insights/publications/2013/11/whistleblowing--an-employers-guide-to-glob al-com_/

Jubb, P. B. (1999). Whistleblowing: A restrictive definition and interpretation. Journal of Business Ethics, 21, 77-94.

Mail \& Guardian. (2009). ANC whistleblower killed. Retrieved from http://mg.co.za/print/2009-01-05-anc-whislteblower-killed

Mail \& Guardian. (2014). Hawks whistle-blower slain. Retrieved from http://mg.co.za/print/2014-09-18-hawks-whistle-blower -slain

Martin, P. (2010). The status of whistleblowing in South Africa-Taking stock. Open Democracy Advice Centre (ODAC), Cape Town.

Moller-Holst, C. (n.d.). Summary of the United Nations Convention against Corruption. Global Advice Network.

ODAC (Open Democracy Advice Centre). (2015). Heroes under fire: South African whistle-blowers stories. March 2015.

Republic of South Africa. (2000). The Protected Disclosures Act 2000 (Act No. 26 of 2000). Pretoria, South Africa.

Republic of South Africa. (2011). Practical guidelines for employees-The Protected Disclosures Act 2000 (Act No. 26 of 2000). Pretoria, South Africa.

Right2Know. (2014). R2K whistleblowers 2015: Buyisile Mkavu. Retrieved from http://www.r2k.org.za/2914/12/12/r2k-whistle wers-2015-buyisile-mkavu

Southern African Development Community. (2001). Protocol Against Corruption. Retrieved from http://www.sadc.int/files/7913/ 5292/8361/Protocol_Against_Corruption2001.pdf

Tilley, A. (2014). Of (silver) bullets and whistleblowers. Daily Maverick. Retrieved from www.dailymaverick.co.za/opionista/ 2014-04-16-of-silver-bullets-and-whistleblowers

United Nations. (2015). United Nations Conventions against Corruption-Signature and ratification status as of 12 November 2014. United Nations Office on Drugs and Crime. Retrieved from http://www.unodc.org/unodc/en/treaties/CAC/signatories. html

Uys, T. (2008). Rational loyalty and whistleblowing: The South African context. Current Sociology, 56(6), 904-921.

Whistleblower (Pty) Ltd. (2015). Whistle blowers-Independent whistleblowing service. Retrieved from http://www.whistle blowing.co.za/

Yeoh, P. (2014). Whistleblowing: Motivations, corporate self-regulation, and the law. International Journal of Law and Management, 56(6), 459-474. 